\title{
Akt and mTOR mediate programmed necrosis in neurons
}

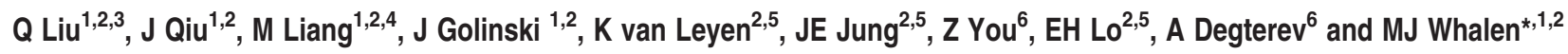

Necroptosis is a newly described form of regulated necrosis that contributes to neuronal death in experimental models of stroke and brain trauma. Although much work has been done elucidating initiating mechanisms, signaling events governing necroptosis remain largely unexplored. Akt is known to inhibit apoptotic neuronal cell death. Mechanistic target of rapamycin (mTOR) is a downstream effector of Akt that controls protein synthesis. We previously reported that dual inhibition of Akt and mTOR reduced acute cell death and improved long term cognitive deficits after controlled-cortical impact in mice. These findings raised the possibility that Akt/mTOR might regulate necroptosis. To test this hypothesis, we induced necroptosis in the hippocampal neuronal cell line HT22 using concomitant treatment with tumor necrosis factor $\alpha$ (TNF $\alpha)$ and the pan-caspase inhibitor N-benzyloxycarbonyl-Val-Ala-Asp-fluoromethylketone. TNF $\alpha / z V A D$ treatment induced cell death within $4 \mathrm{~h}$. Cell death was preceded by RIPK1-RIPK3-pAkt assembly, and phosphorylation of Thr-308 and Thr473 of AKT and its direct substrate glycogen synthase kinase-3 $\beta$, as well as mTOR and its direct substrate 66 ribosomal protein (S6), suggesting activation of Akt/ mTOR pathways. Pretreatment with Akt inhibitor viii and rapamycin inhibited Akt and S6 phosphorylation events, mitochondrial reactive oxygen species production, and necroptosis by over $50 \%$ without affecting RIPK1-RIPK3 complex assembly. These data were confirmed using small inhibitory ribonucleic acid-mediated knockdown of AKT1/2 and mTOR. All of the aforementioned biochemical events were inhibited by necrostatin-1, including Akt and mTOR phosphorylation, generation of oxidative stress, and RIPK1-RIPK3-pAkt complex assembly. The data suggest a novel, heretofore unexpected role for Akt and mTOR downstream of RIPK1 activation in neuronal cell death.

Cell Death and Disease (2014) 5, e1084; doi:10.1038/cddis.2014.69; published online 27 February 2014

Subject Category: Neuroscience

Necroptosis is a form of programmed necrosis regulated by the kinase activity of receptor-interacting protein kinase 1 (RIP1; also known as RIPK1) and RIP3 (also known as RIPK3). Necroptotic stimuli induce TNF receptor 1 complex assembly involving TNFR- associated death domain protein, Fas-associated death domain protein, caspase-8, RIPK1, RIPK3, and various regulator molecules such as FADD-like interleukin-1 beta converting enzyme (FLICE)-like inhibitory protein and cylindromatosis protein, among others. The complex formed by RIPK1-RIPK3 defines the necrosome, which is required for initiation of necroptotic cell death. ${ }^{1}$ Necroptosis contributes to neuronal death in experimental models of stroke and traumatic brain injury. ${ }^{2,3}$ Recently, intensive research effort has been directed towards elucidating mechanisms that contribute to necroptosis execution, revealing critical roles for the kinase activity of RIP1 and RIP3, as well as the presence of the mixed lineage kinase domainlike protein, ${ }^{4,5}$ the mitochondrial fission protein regulator dynamin-related protein- $1^{6}$ and reactive oxygen species (ROS). ${ }^{2}$ RIPK1 activity and necrosome complex assembly is regulated by ubiquitylation and deubiquitylation reactions mediated by cylindromatosis protein ${ }^{7}$ and others. Although a number of reports have elucidated mechanisms of necroptosis initiation, little is known about the signaling and execution mechanisms downstream of the necrosome, and how necroptosis is governed in neuronal cells remains unexplored. $^{8-10}$

We recently reported that, surprisingly, combination-pharmacological inhibition of Akt and mechanistic target of rapamycin (mTOR) reduced necrotic cell death in CA3 and CA1 regions of hippocampus and improved functional outcome after controlled-cortical impact $(\mathrm{CCl})$ in mice. ${ }^{11}$

\footnotetext{
${ }^{1}$ Department of Pediatric Critical Care Medicine, Massachusetts General Hospital and Harvard Medical School, Charlestown, MA, USA; ${ }^{2}$ Neuroscience Center, Massachusetts General Hospital and Harvard Medical School, Charlestown, MA, USA; ${ }^{3}$ Department of Anatomy, Histology and Embryology, Shanghai Medical College, Fudan University, Shanghai, China; ${ }^{4}$ Department of Rheumatology, Huashan Hospital, Fudan University, Shanghai, China; ${ }^{5}$ Neuroprotection Research Laboratory, Departments of Neurology and Radiology, Massachusetts General Hospital and Harvard Medical School, Charlestown, MA, USA and ${ }^{6}$ Department of Biochemistry, Sackler School of Graduate Biomedical Sciences, Tufts University, Boston, MA, USA

${ }^{*}$ Corresponding author: MJ Whalen, Department of Pediatric Critical Care Medicine, Massachusetts General Hospital and Harvard Medical School, 149 13th Street, Charlestown, MA 02129, USA. Tel: +1 617724 4380; Fax: +1 617724 4391; E-mail: MWhalen@ Partners.org

Keywords: necroptosis; neuron; Akt; mTOR; RIPK1; RIPK3

Abbreviations: mTOR, mechanistic target of rapamycin; TNF, tumor necrosis factor; GSK, glycogen synthase kinase; S6, S6 ribosomal protein; ROS, reactive oxygen species; FLIP, FADD-like interleukin-1-beta converting enzyme (FLICE)-like inhibitory protein; CCl, controlled cortical impact; BHA, butylated hydroxyanisole; Nec-1, 7-Cl-O-methyl-necrostatin-1; LOX-1, LOXBlock-1; Bai, baicalein; HMGB1, high mobility box group-1 protein; CHX, cyclohexamide; PI, propidium iodide; siRNA, small inhibitory ribonucleic acid; EDTA, ethylenediaminetetraacetic acid; IP, immunoprecipitation; JNK, Jun-N-kinase; FOXO, Forkhead box class O; MAPK, mitogen-activated protein kinase
}

Received 05.8.13; revised 05.1.14; accepted 28.1.14; Edited by D Bano 
These observations, along with our previous data suggesting the contribution of RIP1 kinase-dependent necroptosis to $\mathrm{CCl}^{3}$ suggested a possible role for Akt/mTOR signaling in programmed necrosis in neuronal cells. These in vivo studies in the mouse $\mathrm{CCl}$ model prompted us to examine directly whether Akt and mTOR mediate programmed necrosis in neuronal cells. To this end, we used hippocampal HT22 cells to test the hypothesis that RIPKI-RIPK3 mediated necroptosis is regulated downstream of necrosome assembly by Akt and mTOR. Herein, we report activation of Akt/mTOR signaling pathways and neuronal cell death that are inhibited by pharmacologic or genetic inhibition of Akt and mTOR together. Inhibition of Akt/mTOR did not affect necrosome complex assembly but inhibited oxidative stress and cell death. The data suggest an unexpected role for Akt/mTOR in the regulation of neuronal necrosis. Given a large number of Akt and mTOR inhibitors currently under development, this mechanism of acute neuronal cell death could be highly amenable for therapeutic intervention.

\section{Results}

TNF $\alpha / z V A D$ induces necrosis in HT22 cells. To assess signaling pathways that might mediate necroptosis downstream of RIPK1, we began by establishing conditions that induce necroptosis in HT22 cells using tumor necrosis factor- $\alpha(T N F \alpha)$ and zVAD administration. Dose-response studies of TNF $\alpha$ and $z$ VAD separately determined optimal concentrations of each reagent that together promote necroptosis (Figure 1). We found that $1 \mathrm{ng} / \mathrm{ml} \mathrm{TNF} \alpha$ and $50 \mu \mathrm{M}$ zVAD efficiently induced cell death and, therefore, these conditions were used subsequently in all experiments (Figures $1 \mathrm{a}-\mathrm{c}$ ). TNF $\alpha / \mathrm{zVAD}$ treatment induced membrane permeability to propidium iodide (PI) (Figure 1c) as well as a

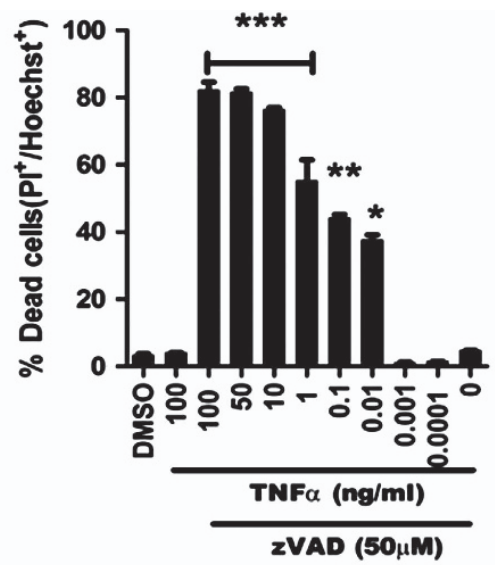

c
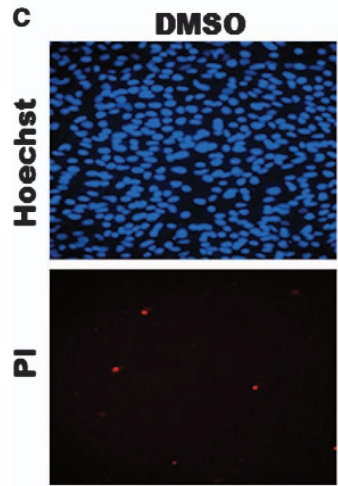

e

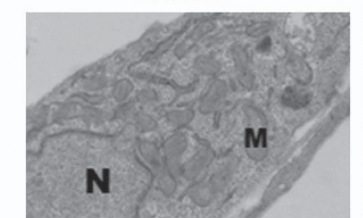

TNF $\alpha / z$ VAD
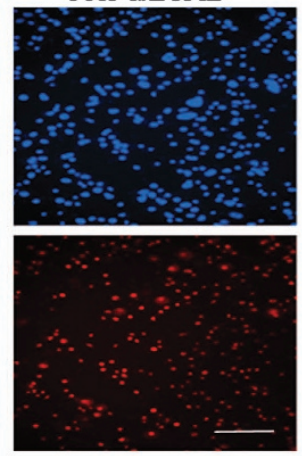

TNFa/zVAD 4h

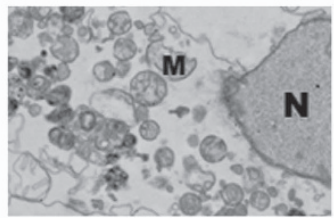

d

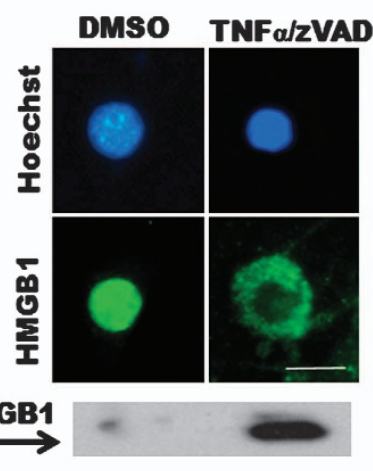

TNFa/zVAD 24h

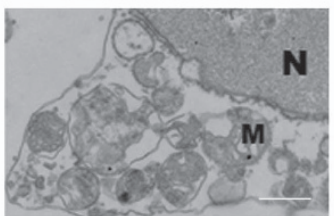

Figure 1 TNF $\alpha /$ ZVAD induces necrosis in HT22 cells. (a, b) TNF $\alpha$ and zVAD dose-response curves. Cell death was assessed by propidium iodide (PI) and Hoechst staining. (c) Representative images of HT22 cells treated with DMSO or TNF $\alpha(1 \mathrm{ng} / \mathrm{ml}) / \mathrm{zVAD}(50 \mu \mathrm{M})$ for $4 \mathrm{~h}$. (d) HMGB1 translocation was detected in cells (blue: Hoechst dye; green: HMGB1 antibody), and in culture media by western blot. (e) Transmission electron microscopy of HT22 cells treated with TNF $\alpha / \mathrm{zVAD}$ for 4 or $24 \mathrm{~h}$ shows necrotic morphology including swollen mitochondria, cytoplasmic clearing, membrane damage, and chromatinolysis. $\mathrm{M}$, mitochondrion; N, nucleus. (All data are presented as mean \pm S.E.M. from $3-5$ independent experiments. ${ }^{\star} P<0.05 ;{ }^{* \star} P<0.01 ;{ }^{* \star} P<0.001$ versus DMSO group.) Scale bars: $\mathrm{c}, 100 \mu \mathrm{m} ; \mathrm{d}, 10 \mu \mathrm{m} ; \mathrm{e}, 1 \mu \mathrm{m}$ 
early translocation of high mobility box group-1 protein (HMGB1) from nucleus to cytosol (Figure 1d), suggesting necrosis. Electron microscopy confirmed ultrastructural features of necrosis including swollen mitochondria, cytoplasmic clearing, membrane damage, and characteristic nuclear changes (Figure 1e). Thus, HT22 cells die by necrosis in response to TNF $\alpha / z V A D$.

TNF $\alpha / z V A D$-induced cell death in HT22 cells is necroptosis. To determine whether TNF $\alpha$ induces necroptosis, for example, RIPK1/RIPK3-dependent programmed necrosis, HT22 cells were treated with TNF $\alpha / z V A D$ in the presence or absence of the potent and specific RIPK1 inhibitor 7-Cl-O-necrostatin-1 (referred to as Nec-1 hereafter), an optimized analog of necrostatin-1 that showed no off-target inhibitory activity in a screen of over 400 human kinases. ${ }^{12-14} \mathrm{Nec}-1$ dose dependently inhibited cell death in response to TNF $\alpha / z V A D$ (Figures $2 a$ and $b$ ). To further validate the role of $\mathrm{Nec}-1$, we used an $\mathrm{N}$-methyl inactive analog of 7-Cl-O-necrostatin-1 that lacks inhibitory activity ${ }^{12}$ and showed that cell death was no longer inhibited, strongly suggesting that HT22 cell death was necroptosis. To further pursue necroptosis as the specific mode of death we employed genetic knockdown of RIPK3 using specific small inhibitory ribonucleic acid (siRNA). Figure 2 shows robust reduction of RIPK3 protein after $72 \mathrm{~h}$ treatment with RIPK3specific siRNA and potent inhibition of TNF $\alpha / z V A D$-induced cell death, strongly suggesting involvement of both RIPK1 and RIPK3 together in HT22 necrosis (Figures $2 \mathrm{c}$ and d). Necroptosis in non-neuronal cells requires formation of a RIPK1-RIPK3 necrosome complex that is dependent on the kinase activity of RIPK1 and RIPK3. ${ }^{15-17}$ To assess for necrosome assembly, we performed immunoprecipitation (IP) experiments that confirmed interaction between RIPK1RIPK3. RIPK1/RIPK3 complex formation was inhibited by $\mathrm{Nec}-1$, as previously reported in non-neuronal cell lines. ${ }^{15}$

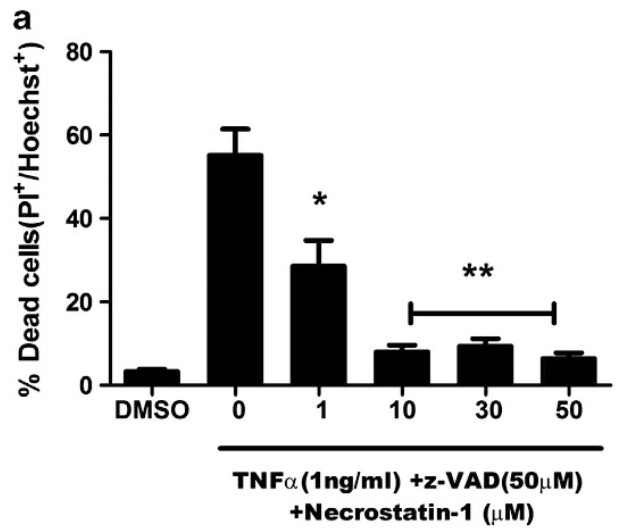

b

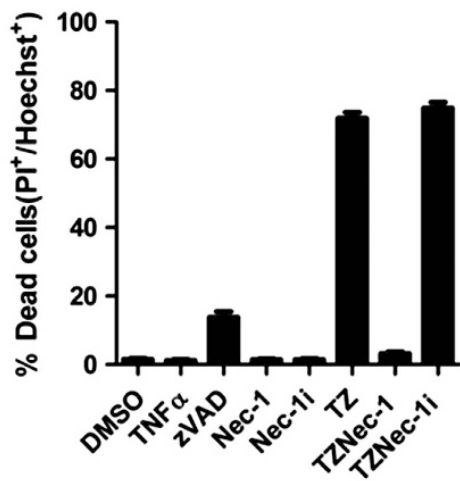

d

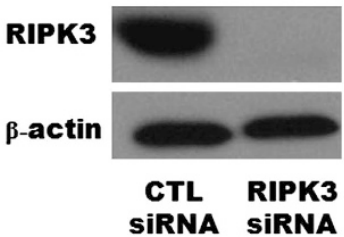

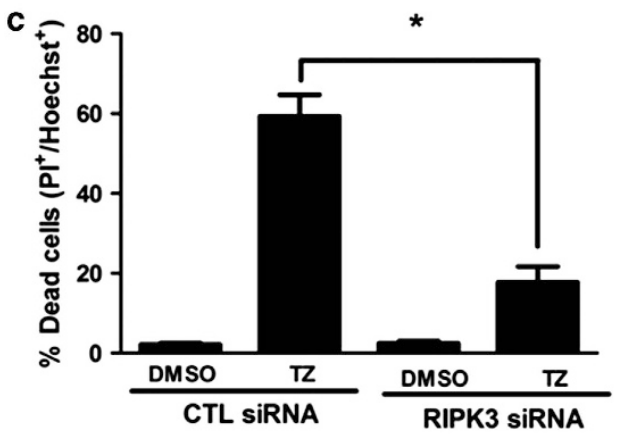

IP: RIPK1
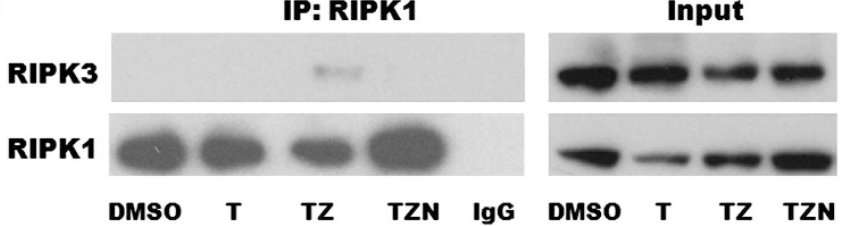

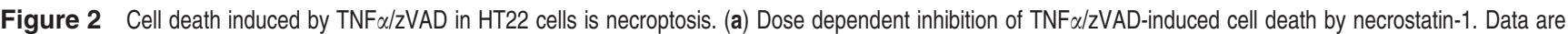
mean \pm S.E.M. from three independent experiments. ${ }^{*} P<0.01$; ${ }^{*} P<0.001$ versus TNF $\alpha(1 \mathrm{ng} / \mathrm{ml}) / \mathrm{zVAD}$ (50 uM) (TZ) alone. (b) The specific RIPK1 kinase inhibitor, 7-Cl-Onecrostatin-1 (Nec-1) but not inactive analog (7-Cl-O-Nec-1; Nec-1i) prevented cell death induced by TNF $\alpha$ and ZVAD. $p=$ ns TZ versus TZ Nec-1i. (c) Knockdown of RIPK3 by specific siRNA suppressed TNF $\alpha / z V A D$-induced cell death. ${ }^{*} P<0.001$ versus negative siRNA treated with TNF $\alpha / z V A D$. (d) Western blot analysis of RIPK3 knockdown. (e) Representative immunoprecipitation experiment $(n=3)$ showing RIPK1-RIPK3 complex assembly in TNF $\alpha / z$ VAD-treated HT22 cells. Complex assembly was inhibited by Nec-1. T, TNFa $(1 \mathrm{ng} / \mathrm{ml}) ; \mathrm{TZN}, \mathrm{TNF} \alpha(1 \mathrm{ng} / \mathrm{ml}) / \mathrm{ZVAD}(50 \mu \mathrm{M}) / \mathrm{Nec}-1(30 \mu \mathrm{M})$. Data are mean and S.E.M. of three independent experiments 
Inhibition of RIPK1/RIPK3 interaction by $\mathrm{Nec}-1$ was not explained by a reduction in protein level as shown by western blot of input sample homogenates (Figure 2e). From these experiments, we conclude that HT22 cell death in response to TNF $\alpha / z V A D$ is necroptosis, in this case dependent upon both RIPK1 and RIPK3, and that at least part of the protective effects of necrostatin-1 involves inhibition of RIPK1/RIPK3 complex assembly.

Necroptosis in HT22 cells is dependent on ROS. Necroptosis in some, but not all, cell lines has been shown to depend on generation of ROS. ${ }^{2,16,18}$ To determine whether generation of ROS has a role in TNF $\alpha / z V A D$-induced necrosis in HT22 cells we used Mitosox red, which detects mitochondrial ROS as well as a number of other potential ROS species. ${ }^{19}$ Mitosox-positive cells were increased by $\mathrm{TNF} \alpha / \mathrm{zVAD}$ treatment and this increase was strongly inhibited by $\mathrm{Nec}-1$, indicating that ROS are generated downstream of RIPK1 (Figures $3 a$ and b). ROS generation was also inhibited by Akt viii/rapamycin, suggesting Akt and mTOR signaling is upstream of ROS production (Figures $3 a$ and b). ROS generation (not shown) and HT22 cell death (Figure 3c) was dose dependently inhibited by the antioxidant betahydroxyanisole, and cell death was blocked by a number of other antioxidants including rotenone (a mitochondrial complex I inhibitor) and the lipoxygenase inhibitor baicalein (Bai; Figure 3c). Another lipoxygenase inhibitor that does not have antioxidant activity itself but is known to reduce oxidative stress-related cell death in HT22 cells, LOXBlock-1 (LOX-1), ${ }^{20,21}$ also protected against TNFa/ZVAD to the same extent as bai and rotenone. Thus, ROS generation is required for necroptosis in HT22 cells.

TNF $\alpha / z$ VAD activates Akt and mTOR signaling pathways in HT22 cells. Curiously, previous studies in cancer cells suggested that Akt activity may promote, rather than inhibit ROS-induced cell death due to transcriptional downregulation of antioxidant defenses. Our recent study suggested that in a specific case of mouse fibrosarcoma L929 cell line Akt and mTOR activation contributes to necroptosis. ${ }^{22-24}$ However, this was not observed in a number of other cell lines, where Akt was linked to TNF $\alpha$ synthesis but not cell death, suggesting that pronecroptotic signaling may be limited to L929 cells. However, given our previous data regarding the roles of Akt and $\mathrm{mTOR}$ in $\mathrm{CCl}$, we assessed for activation of Akt and mTOR pathways in TNF $\alpha / z V A D$-treated $\mathrm{HT} 22$ cells at $2 \mathrm{~h}$. We chose this early time point because it is before the onset of detectable cell death in our model system. In response to TNF $\alpha / z V A D$, Akt was phosphorylated at the 473 and 308 sites along with glycogen synthase kinase (GSK)-3 $\beta$ (Ser9), a direct substrate of Akt, and mTOR and its direct substrate S-6 (Figures 4a and c). In contrast to L929 cells induced to necroptosis by TNF $\alpha$ alone in which Akt phosphorylation was transient early on but sustained several
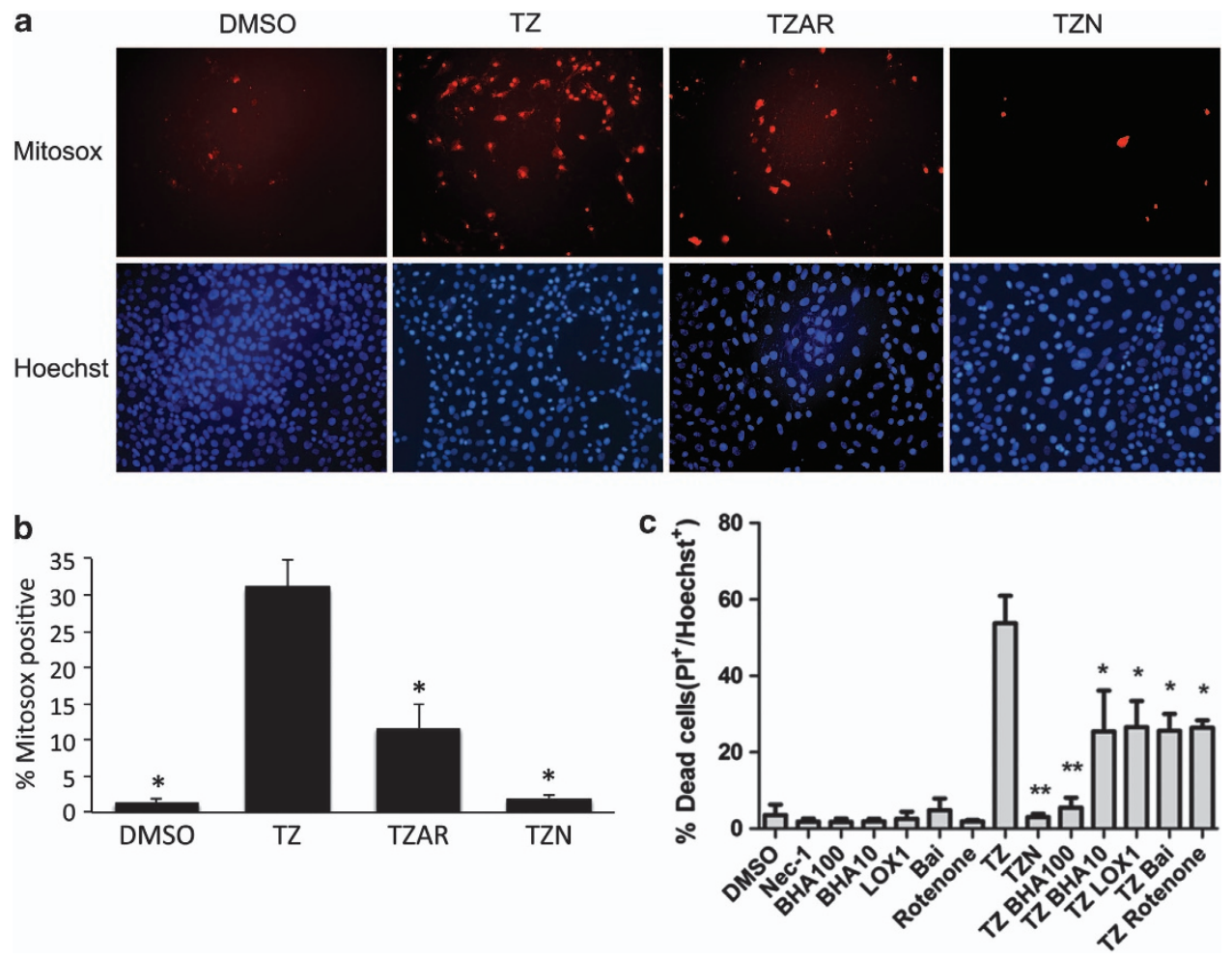

Figure 3 Cell death induced by TNF $\alpha / z V A D$ is associated with oxidative stress. (a) Representative $\times 200$ photomicrographs showing MitoSox Red and Hoechst fluorescence in HT22 cells $4 \mathrm{~h}$ after treatment with dimethylsulfoxide vehicle (DMSO), TNF $\alpha / z V A D(T Z)$, or TNF $\alpha / z V A D$ treatment in the presence or absence of Akt/mTOR inhibitors (TZAR, TZ + Akt inhibitor VIII (10 uM) + rapamycin (100 nM)) or necrostatin-1 (30 uM; TZN). (b) MitoSox-positive cells were quantitated by fluorescence microscopy. ANOVA $P<0.0001$. * $P<0.05$ versus TZ for all groups. Data are from four independent experiments. (c) Protective effects of betahydroxyanisole (BHA), LOXBlock-1 (LOX-1) inhibitor, baicalein, and rotenone on TNF $\alpha / z V A D$-induced cell death. Data are from three independent experiments. ${ }^{*} P<0.05$; ${ }^{\star \star} P<0.01$ versus TNF $\alpha / z V A D(T Z)$ group. TZN, TNF $\alpha /$ ZVAD/Nec-1 $(30 \mu \mathrm{M})$ 
hours later, ${ }^{23}$ Akt and mTOR phosphorylation in HT22 cells was detectable as early as $30 \mathrm{~min}$ after addition of TNF $\alpha / z V A D$ and was sustained throughout the entire experimental period (Figures $4 \mathrm{a}$ and $\mathrm{c}$ and data not shown). Phosphorylation of Akt and $\mathrm{mTOR}$ and their related substrates was not induced by TNF $\alpha$ or zVAD alone but required specific necroptotic signaling by $T N F \alpha / z V A D$ together (Figures $4 \mathrm{~b}$ and $\mathrm{d}$ ). Necrostatin-1 pretreatment inhibited the increase in Akt-308 and -473 , as well as that of mTOR and Akt and downstream mTOR substrates, confirming that phosphorylation and activation of Akt/mTOR in response to TNF $\alpha / Z V A D$ is RIPK1 dependent and represent sequelae of necroptosis signaling downstream from RIPK1 (Figures 5b and c). Notably, treatment of HT22 cells with TNF/cyclohexamide $(\mathrm{CHX})$ induced widespread death by $18 \mathrm{~h}$ but did not induce Akt phosphorylation at $2 \mathrm{~h}$ (Figure $4 \mathrm{e}$ ) or $18 \mathrm{~h}$ (data not shown), suggesting that Akt activation in HT22 cells treated with TNF/zVAD is specific for necroptosis.

To test functionality of Akt and mTOR activation, we used two different approaches. First, we treated HT22 cells with Akt inhibitor viii, rapamycin, or both and assessed cell death by $\mathrm{PI}$ staining and pathway inhibition by western blot. Administration of Akt and mTOR inhibitors together reduced HT22 cell death to a greater extent than Akt or mTOR inhibitors alone, suggesting that both pathways participate in necroptosis signaling (Figure 5a). Cell death was also reduced by treatment with Akt inhibitor viii and torin II, a more specific inhibitor of mTOR than rapamycin (data not shown). Western blot and densitometric analyses confirmed inhibition of phosphorylation of Akt and mTOR and their substrates by Akt inhibitor viii and rapamycin, respectively (Figures $5 b$ and $c$ ).

In a second approach to mitigate the potential problem of off-target effects that could confound interpretation of pharmacological experiments, we used specific siRNA to knockdown Akt 1 and 2 (Akt 3 was not detected in HT22 cells; Figure 6a) and mTOR (Figures $6 \mathrm{~b}$ and $\mathrm{c}$ ), and assessed the effect of genetic inhibition of each in TNF $\alpha / z V A D$-induced cell death. In each case robust knock down of protein was obtained, and HT22 cells administered siRNA against Akt1/2 and mTOR together had reduction in TNF $\alpha / z V A D$-induced death similar in magnitude to treatment with chemical Akt and mTOR inhibitors (Figure 6d). Thus, chemical and genetic approaches each suggested a role for Akt and mTOR activation in programmed necrosis of HT22 cells.

Akt/mTOR inhibition does not affect RIPK1-RIPK3 complex assembly in TNF $\alpha / z$ VAD-treated HT22 cells. Previous studies have demonstrated an essential role for a

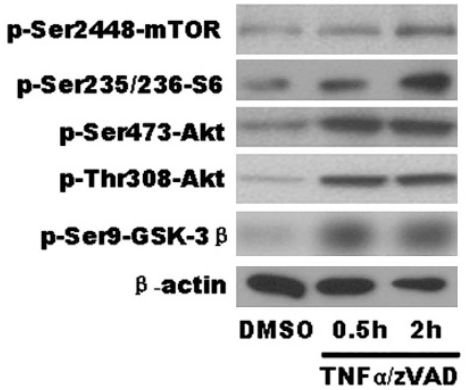

b
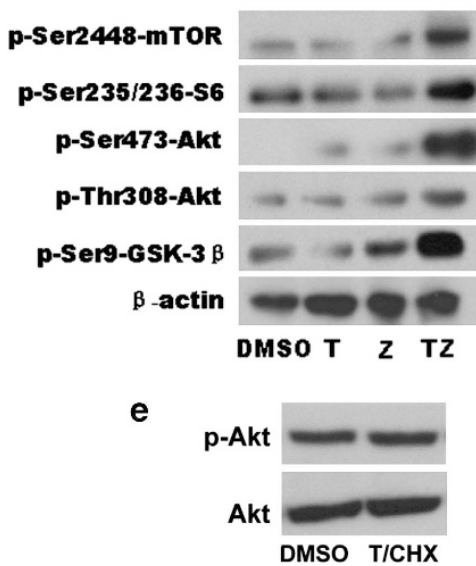
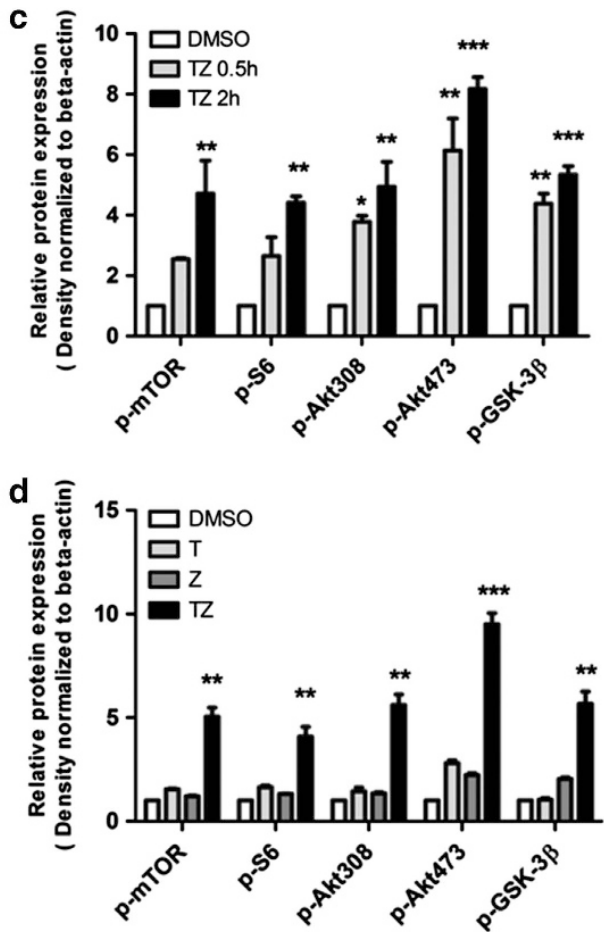

Figure 4 Activation of Akt/mTOR after TNF $\alpha / z$ VAD treatment. Representative immunoblots $(\mathbf{a}, \mathbf{b})$ and densitometry results (c, d) of Akt/mTOR activation in HT22 cells after TNF $\alpha / z V A D$ or vehicle dimethylsulfoxide treatment. (a) Time course of phosphorylation events downstream of Akt/mTOR ( $n=3$ independent experiments). (c) Densitometry data from a. (b) Synergistic effect of TNF $\alpha$ and ZVAD is required to activate Akt/mTOR signaling in HT22 cells. (d) Densitometry data from b. (e) Representative western blot analysis of Akt phosphorylation $2 \mathrm{~h}$ after treatment with TNF/cyclohexamide to induce apoptotic cell death. No change in pAkt-473 or total Akt was observed using apoptotic stimuli. ${ }^{*} P<0.05$; ${ }^{* *} P<0.01 ;{ }^{* * *} P<0.001$ versus DMSO group. Data are from $n=3$ independent experiments. Abbreviations: phospho-Ser473-Akt (p-Akt-473), phospho-Ser308-Akt (p-Akt-308), phospho-Ser9-GSK-3 $\beta$ (p-GSK-3 $\beta$ ), phospho-Ser2448-mTOR (p-mTOR) and phospho-Ser235/236 S6 (p-S6) 
a

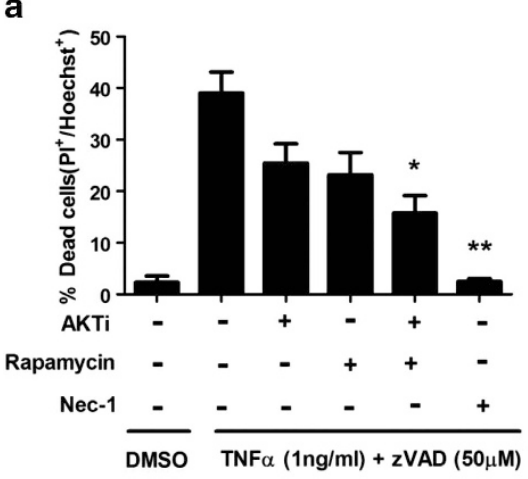

b

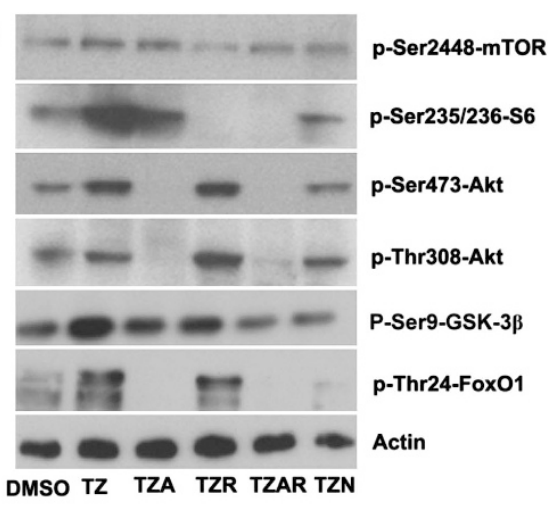

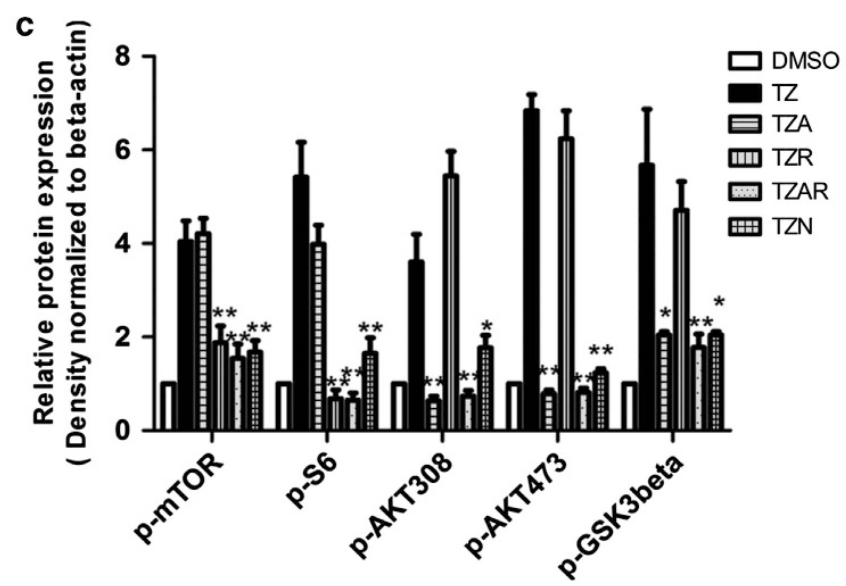

Figure 5 Dual inhibition of Akt and mTOR inhibits necroptosis induced by TNF $\alpha / Z V A D$. (a) Akt and mTOR inhibitors reduced cell death induced by TNF $\alpha / z$ VAD as detected by propidium iodide (PI) and Hoechst staining. (b, c) Representative immunoblots and densitometry for phosphorylated Akt, GSK-3 $\beta$, FoxO1, mTOR, and S6 in HT22 cells after TNF $\alpha / \mathrm{zVAD}$ in the presence or absence of Akt inhibitor VIII $(10 \mathrm{uM})$ and rapamycin $(100 \mathrm{nM})$ (data are three independent experiments, ${ }^{*} P<0.01 ;{ }^{*} P<0.001$ compared with TZ group). Abbreviations: TNF $\alpha(1 \mathrm{ng} / \mathrm{ml}) / \mathrm{ZVAD}(50 \mu \mathrm{M}) / \mathrm{Akt}$ inhibitor VIII $(10 \mu \mathrm{M})(\mathrm{TZA}), \mathrm{TNF} \alpha(1 \mathrm{ng} / \mathrm{ml}) / \mathrm{zVAD}(50 \mu \mathrm{M}) / \mathrm{rapamycin}(100 \mathrm{nM})(\mathrm{TZR})$, $\mathrm{TNF} \alpha(1 \mathrm{ng} / \mathrm{ml}) / \mathrm{ZVAD}(50 \mu \mathrm{M}) / \mathrm{Akt}$ inhibitor VIII $(10 \mu \mathrm{M}) /$ rapamycin $(100 \mathrm{nM})(\mathrm{TZAR})$
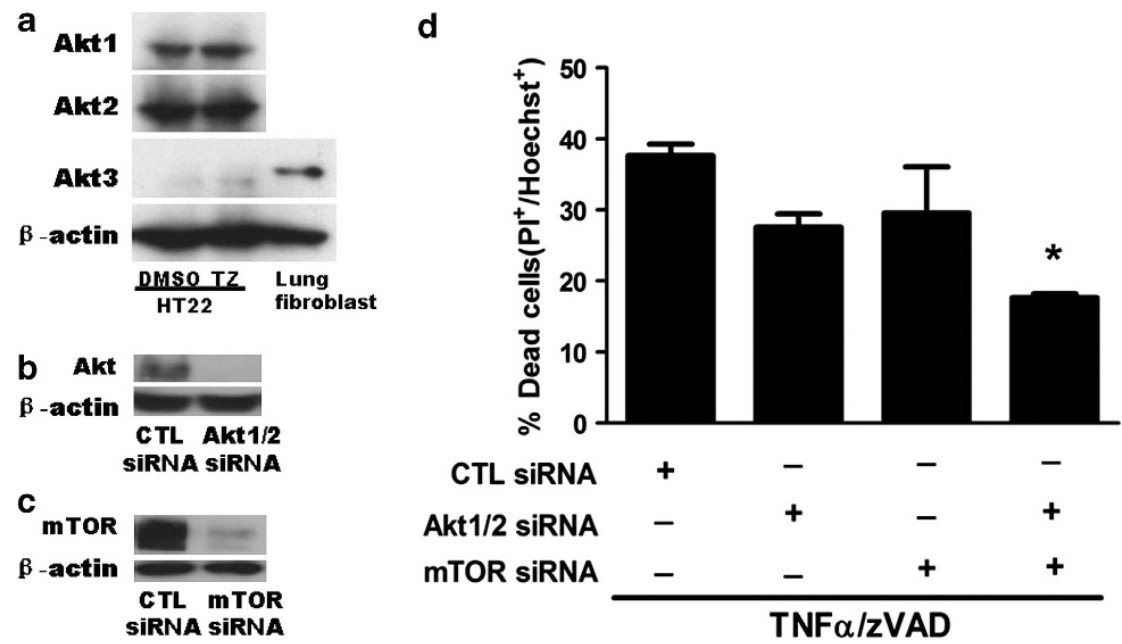

TNF $\alpha / z V A D$

Figure 6 Knockdown of Akt and mTOR inhibits necroptosis induced by TNFa/zVAD. (a) HT22 cells expressed Akt1 and Akt2 but not Akt3 determined by immunoblot. Mouse lung fibroblasts were used as Akt3 positive control. (b, c) siRNA-mediated knockdown of mTOR, Akt1, and Akt2 in HT22 cells was confirmed by immunoblot using reagents identifying total Akt and mTOR. (d) Cell death was determined in control cells and in cells with knockdown of Akt1/2, mTOR, or triple knockdown of mTOR and Akt1/ Akt2 together. Data are representative of three independent experiments, ${ }^{*} P<0.05$ versus control (CTL) siRNA

kinase activity of RIPK1/RIPK3 in assembly of the necrosome complex. ${ }^{4,15-17}$ To determine whether Akt/mTOR activation might also have a role in RIPK1/RIPK3 complex assembly, HT22 cells were treated with TNF $\alpha / z V A D$ in the presence or absence of Akt inhibitor viii and rapamycin, and RIPK1-RIPK3 interaction was assessed by IP. Akt/mTOR 


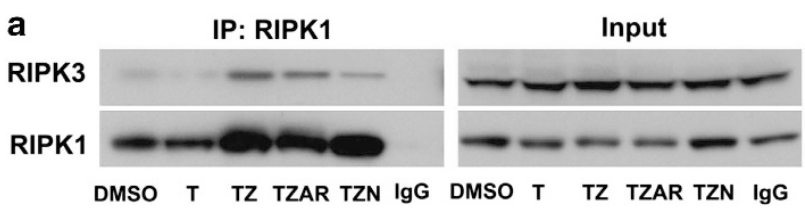

b IP: RIPK1

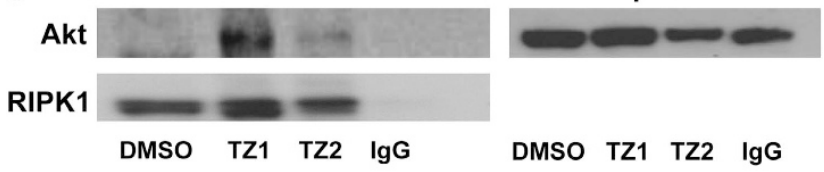

c

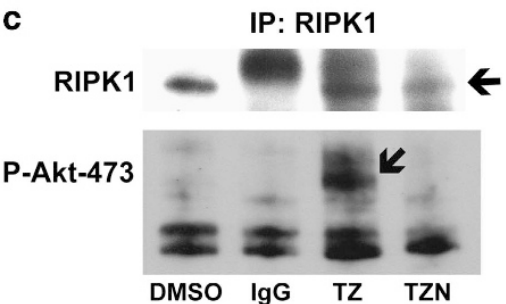

Figure 7 RIPK1-RIPK3 complex assembly occurs upstream of Akt/mTOR activation and reactive oxygen species (ROS) generation after TNF $\alpha / z V A D$ treatment. Interaction between RIPK1-RIPK3 (a) and RIPK1-Akt (b) was detected by immunoprecipitation (IP) and western blot analysis. (c) RIPK1-p-Akt-473 interaction (arrow) was also detected at $2 \mathrm{~h}$ after TNF/ZVAD (TZ) treatment. Detection of p-Akt-473 was abolished by pretreatment with necrostatin-1 (TZN, $30 \mathrm{uM}$ ). Control experiments showed the presence of RIPK1 in immunoprecipitants from all of the groups except those immunoprecipitated with irrelevant lgG. DMSO, dimethylsulfoxide control. Data are representative of three independent experiments

inhibition did not affect RIPK1-RIPK3 interaction (Figure 7a), suggesting that $A \mathrm{kt} / \mathrm{mTOR}$ activation occurs downstream of RIPK1-RIPK3 complex assembly and prior to necroptosis steps that produce oxidative stress. These data also raised the possibility of direct interaction of Akt with the necrosome and regulation of its phosphorylation and activation by RIPK1. Indeed, total Akt as well as phospho-Akt-473 was detected in RIPK1 immunoprecipitants in TNF/ZVADstimulated HT22 cells, and phospho-Akt-473 interaction with RIPK1 was undetectable with pretreatment of cells with necrostatin-1 (Figures $7 \mathrm{~b}$ and c). Inhibition of pAkt-RIPK1 interaction by Nec-1 was not due to lack of RIPK1 protein as confirmed by IP (Figure 7c). These data suggest that Akt complexes with RIPK1 and RIPK3, and that its activity during necroptosis may be regulated by necrosome activity.

\section{Discussion}

Elucidating mechanisms of neuronal necroptosis is an important area of investigation considering the growing number of reports suggesting its involvement in acute central nervous system injury, including ischemia/reperfusion, trauma, and intracerebral hemorrhage..$^{2,3,25,26}$ Despite a significant research effort to characterize the molecular machinery of necroptosis, little is known regarding the components of necroptosis signaling downstream of necrosome assembly, and almost nothing is known about the regulation of necroptosis in neuronal cells. ${ }^{8-10}$ Necroptosis in HT22 cells exhibited all of the cellular and biochemical features of necrosis reported in non-neuronal cells including assembly of a RIPK1-RIPK3 necrosome complex, generation of ROS, sensitivity to Jun-N-kinase (JNK) and ROS inhibitors, ${ }^{2,23,27,28}$ loss of mitochondrial membrane potential and adenosine triphosphate depletion, and characteristic ultrastructural features., ${ }^{2,15-17}$ Protection by the specific RIPK1 inhibitor 7-Cl-O-necrostatin-1 and by RIPK3 knockdown confirmed necroptotic cell death in this model system.

We previously reported that pharmacological inhibition of Akt and mTOR reduced early cell death in CA1 and CA3 after $\mathrm{CCl}$ in mice, suggesting a novel role for Akt and mTOR in the pathogenesis of traumatic brain cell death. ${ }^{11}$ These observations prompted us to examine the role of Akt and mTOR in necroptosis signaling in neuronal cells. We found that administration of TNF $\alpha / z V A D$ (but not TNF $\alpha$ or ZVAD alone) induced rapid and sustained phosphorylation of Akt on Thr-308 and Ser-473 and mTOR, as well as phosphorylation of direct substrates of Akt (GSK-3 $\beta$, forkhead box class O (FOXO)-1) and mTOR (S6 ribosomal protein (S6)). All of these phosphorylation events were inhibited by necrostatin-1, a potent and highly specific RIPK1 inhibitor. ${ }^{12}$ IP experiments showed that TNF/ZVAD induced RIPK1-Akt and RIPK1pAkt-473 interaction. Necrostatin-1 treatment rendered RIPK1-pAkt-473 interaction undetectable, consistent with inhibition of phosphorylation of Akt by the necrosome. Alternatively, necrostatin-1 may prevent binding of Akt to RIPK1. To our knowledge, the data are the first to show a direct interaction of Akt with RIPK1, and provide a molecular link between necrosome assembly and Akt activation during neuronal necroptosis.

Akt/mTOR inhibition did not affect RIPK1-RIPK3 interaction but inhibited ROS production and cell death. Importantly, genetic inhibition of Akt and mTOR together reduced cell death by a magnitude similar to that of pharmacological inhibitors, confirming a specific role for Akt and mTOR. Taken together, the data indicate that Akt/mTOR mediate necroptosis signaling downstream of the necrosome assembly and before the production of ROS and onset of plasmalemma damage. The observation that concomitant inhibition of Akt and mTOR together was required for maximal protection is reminiscent of our findings in the $\mathrm{CCl}$ model, and suggests divergent roles for Akt and mTOR in necroptotic signaling in neuronal cells. In contrast, Akt activation was not involved in apoptosis of HT22 cells treated with TNF and $\mathrm{CHX}$ (Figure 4e).

In the current study, antagonism of Akt and mTOR together was required to maximally inhibit necroptosis in HT22 cells. These findings are in agreement with our previous in vivo study in which Akt and mTOR inhibitors together were required to reduce necrotic cell death and improve postinjury cognitive function after cerebral contusion in mice. ${ }^{11}$ Thus, regulation of necroptosis by Akt and mTOR together may be a unique property of neuronal cells, or may depend on the exact stimulus used to initiate necroptosis. Akt is activated and is essential for necroptosis in mouse L929 fibroblasts stimulated with TNF $\alpha$ or ZVAD, but not for necroptosis of Fas-associated protein with death domain-deficient Jurkat $\mathrm{T}$ lymphocytes treated with $\mathrm{TNF} \alpha .{ }^{23}$ In mouse lung fibroblasts and macrophages, Akt exhibited control over necroptosis-associated TNF $\alpha$ production but did not have a role in cell death. ${ }^{23}$ 
Thus, Akt activation mediates necroptosis in some but not all non-neuronal cell types, and as such is not a uniform defining feature of necroptosis. This idea is supported by data showing partial or complete inhibition of cell death by various antioxidant agents and inhibitors of oxidative stress enzymes (Figure $3 \mathrm{c}$ ). Akt is activated during necroptosis in Jurkat cells but ROS production does not occur, and Akt inhibitors block TNF production but not cell death in this line. ${ }^{2,23}$ Thus, no simple relationship exists between Akt/mTOR activation, ROS production and necroptosis in all cell types.

IP studies performed herein suggest that phosphorylation of Akt may be required for its incorporation into the necrosome complex, as treatment with necrostatin-1 abolished detection of phospho-Akt-473-RIPK1 interaction. These findings suggest that Akt phosphorylation might regulate necroptosis at the level of the necrosome. In the case of L929 cells, Akt Ser-473 was not increased or involved in cell death; however, plasmalemma localization and selective phosphorylation of Akt Thr-308 was required to link RIPK1 to downstream JNK signaling, autocrine TNF $\alpha$ production, and death. ${ }^{23}$ Although the exact mechanism of Thr-308 phosphorylation remains unknown, inhibition of phosphatase $2 \mathrm{~A}$ (a phosphatase that dephosphorylates Thr-308; $45 \mathrm{MnA}$ ) had no effect. ${ }^{23}$ In vitro, recombinant RIPK1 can phosphorylate Akt on Thr146, $195 / 197$, 435, and Ser381 but whether Akt is an endogenous substrate of RIPK1 is not clear. ${ }^{23}$ Further studies are needed to better understand how Akt is regulated by phosphorylation during necroptosis.

Prevailing wisdom assigns a prosurvival role for Akt in CNS injury paradigms including stroke and traumatic brain injury. ${ }^{29-40}$ Antiapoptotic activity of Akt has been well documented, through a number of mechanisms including inhibition of caspase 9, Bad, and GSK-3 $\beta$, and induction of mitochondrial hexokinase and nuclear factor kappa B-dependent antiapoptotic gene expression. ${ }^{41-43}$ Nonetheless, several recent reports illustrate an emerging role for Akt as a 'death kinase' and a key regulator of programmed necrosis, including neuronal cell types, ${ }^{44}$ depending on injury context. Activation of phosphatidylinositol 3 kinase/Akt has been linked to cytotoxic cell death ${ }^{45-48}$ and nuclear translocation of Akt has been reported to sensitize cancer cells to death by chemotherapeutic agents. ${ }^{49,50}$ Akt inhibitors also protect cultured neurons against photodynamic induced necrosis. ${ }^{44}$ Data from the current study raise the question of which Akt/ mTOR substrates might be critical regulators of necroptosis in neuronal cells. Our data suggest a possible role for mTOR complex1-dependent regulation as previously reported by McNamara et al., ${ }^{23}$ as well as the Akt substrates FOXO1, GSK-3 $\beta$, and others. Although further studies are needed to determine the specific mediators downstream of Akt and mTOR, taken together the present data and our previous report ${ }^{11}$ suggest that Akt may promote necrosis in neuronal cell types following acute CNS injury.

How might Akt promote necrotic death? Although limited activation of Akt is antiapoptotic, sustained Akt activity may promote cell death by a number of distinct mechanisms. Strong activation of Akt increases oxygen consumption by increasing glycolysis and oxidative phosphorylation, resulting in generation of ROS and oxidative stress. ${ }^{24,42}$ Sustained Akt activation also induces phosphorylation of forkhead box subclass O (FOXO) transcription factors required for upregulation of antioxidant defenses such as manganese superoxide dismutase, catalase and sestrin-3. ${ }^{51,52}$ Phosphorylated FOXO transcription factors bind to 14-3-3 protein and are excluded from the nucleus, thus rendered transcriptionally inactive, ${ }^{53}$ and sustained phosphorylation promotes their proteosomal degradation. ${ }^{54,55}$ Our finding that the inhibition of $\mathrm{Akt} / \mathrm{mTOR}$ strongly inhibited phosphorylation of FOXO1, reduced generation of ROS and inhibited death in HT22 cells stimulated to necroptosis suggests that Akt/mTOR activation may increase lethal oxidative stress after acute injury to neuronal cells. Finally, sustained Akt activation can constitutively activate cyclin-dependent kinase 2 leading to its cytoplasmic sequestration, cell cycle arrest at G2-M, and induction of cell death. ${ }^{56,57}$ Future studies aimed at pinpointing the exact mechanisms of Akt/mTOR-induced necroptosis are warranted as Akt and mTOR may not be optimal therapeutic targets for neuroprotection because of their protean functions in cells.

Herein, we show that Akt and mTOR together account for $\sim 50 \%$ of the cell death in the conditions used in necroptosis assays. The other mechanism(s) that account for the remainder of necroptotic cell death remain to be discovered. A JNK inhibitor reduced necroptosis in HT22 cells by $\sim 50 \%$; however, we did not observe an additive effect of Akt/mTOR/ JNK inhibitors and no effect of extracellular-regulated kinase or P38 mitogen-activated protein kinase (MAPK) inhibition, consistent with a similar lack of a role for these MAPK in necroptosis of non-neuronal cell types. ${ }^{23,28}$ Interestingly, we previously reported that intracerebroventricular administration of necrostatin-1 reduced necrotic cell death in dentate gyrus and cortex after $\mathrm{CCl}$ in mice. ${ }^{3}$ However, these brain regions were not protected by Akt/mTOR inhibitors in our subsequent study, ${ }^{11}$ consistent with the findings of the current study that necrostatin- 1 is fully and Akt/mTOR inhibitors only partially protective against necrotic cell death in HT22 cells.

In conclusion, we demonstrate for the first time a role for Akt/mTOR signaling governing necroptosis in a neuronal cell line. The data are consistent with a need for dual inhibition of Akt and mTOR to reduce traumatic brain cell death in vivo. ${ }^{11}$ Elucidation of additional necroptosis signaling mechanisms downstream of necrosome assembly will be important to fully understand how necroptosis is regulated in neuronal cells. Such information is likely to yield new therapeutic targets to reduce cell death and improve functional outcome after stroke, traumatic brain injury, and other forms of acute CNS injury.

\section{Materials and Methods}

Reagents. The following materials were purchased from commercial companies: TNF $\alpha$ (PeroTech; Rocky Hill, NJ, USA); pan-caspase inhibitor z-VAD-fmk (Abcam, Cambridge, MA, USA). InSolution Akt Inhibitor viii isozyme-selective, Akti-1/2 and InSolution rapamycin were obtained from Calbiochem (San Diego, CA, USA). MitoSox Red was obtained from Invitrogen (Carlsbad, CA, USA). Hoechst 33258 , butylated hydroxyanisole $(\mathrm{BHA})$ and rotenone were obtained from Sigma (St. Louis, MO, USA). Nec-1 (5-(7-chloro-1H-indol-3-ylmethyl)-3-methylimidazolidine-2,4-dione), the inactive analog of necrostatin-1 analog (Nec-1i; 5-(7-chloro-1H-indol-3-ylmethyl)imidazolidine-2,4-dione), ${ }^{3,12,13}$ was a kind gift from Dr. Greg Cuny. LOX-1 was obtained from Chembridge (compound 5680672; San Diego, CA, USA), and Bai was from Cayman Chemicals (Ann Arbor, MI, USA). 
Antibodies were obtained from commercial sources: anti-pAkt-473, anti-p-Akt-308, anti-p-GSK-3 $\beta$, anti-p-mTOR, anti-p-S6, anti-mTOR, anti-Akt1, anti-Akt2, antiAkt3, and anti-Akt from Cell Signaling (Danvers, MA, USA); anti-RIPK1 from BD Transduction Laboratories (Lexington, KY, USA); anti-RIPK3 from ProSci Incorporated (San Diego, CA, USA); anti-HMGB1 and $\beta$-actin were obtained from Abcam.

Cell culture and treatment protocols. HT22 murine hippocampal neuronal cells were maintained in Dulbecco's modified essential medium supplemented with 10\% (v/v) FBS and antibiotics (penicillin-streptomycin) and incubated at $37^{\circ} \mathrm{C}$ under $5 \% \mathrm{CO}_{2}$. To test the effects of necrostatin-1 $(30 \mu \mathrm{M})$, Nec-1i $(30 \mu \mathrm{M}), \mathrm{BHA}(100$ and $10 \mu \mathrm{M})$, LOX-1 $(5 \mu \mathrm{M})$, Bai $(10 \mu \mathrm{M})$, Akt inhibitor VIII $(10 \mu \mathrm{M})$, and rapamycin $(100 \mathrm{nM})$, cells were pretreated with each of the reagents at the mentioned concentrations for 15 min before the addition of TNF $\alpha$ $(1 \mathrm{ng} / \mathrm{ml})$ and $\mathrm{ZVAD}(50 \mu \mathrm{M})$. Control groups were treated with vehicle (DMSO) only. For experiments examining apoptosis, HT22 cells were treated for 2 or $18 \mathrm{~h}$ with TNF $(10 \mathrm{ng} / \mathrm{ml})$ and $\mathrm{CHX}(10 \mu \mathrm{g} / \mathrm{ml})$.

Detection of cell death using propidium iodide. Propidium iodide $(1 \mu \mathrm{g} / \mathrm{ml}$; Sigma) and Hoechst 33258 (10 $\mu \mathrm{g} / \mathrm{ml}$; Sigma) were added to media and incubated with HT22 cells for 5 min. For quantification of $\mathrm{PI}+$ cells, photographs were randomly taken from three individual $\times 200$ fields per well. There were three wells per experimental condition. $\mathrm{PI}^{+}$cells were expressed as a percentage of Hoechst $^{+}$cells.

Immunocytochemistry. For HMGB1 staining, HT22 cells were fixed with $4 \%$ paraformaldehyde in PBS for $15 \mathrm{~min}$ at room temperature and permeabilized with $0.1 \%$ Triton X-100 in PBS. After blocking with $1 \%$ bovine serum albumin, cells were incubated with primary antibody to HMGB1 (1:100; Cell Signaling) overnight at $4{ }^{\circ} \mathrm{C}$, followed by incubation with a fluorescein isothiocyanate-conjugated goat anti-rabbit lgG $(1: 500)$ at room temperature for $1 \mathrm{~h}$. Hoechst dye was used for nuclear staining.

Transmission electron microscopy. HT22 cells were fixed in PBS containing $2 \%$ paraformaldehyde/2\% glutaraldehyde for $60 \mathrm{~min}$. After washing in the same buffer, cells were gently scraped off with a rubber policeman, centrifuged, and postfixed with $1 \%$ OsO4, $0.8 \%$ potassium ferricianide, and $5 \mathrm{mM}$ $\mathrm{CaCl}_{2}$ in $0.1 \mathrm{M}$ cacodylate buffer. Samples were washed twice in the same buffer, dehydrated in acetone and embedded in PolyBed 812. Ultrathin sections were stained with uranyl acetate and lead citrate and observed in a FEI Morgagni transmission electron microscope operating at $80 \mathrm{kV}$.

RNA interference. siRNA for mouse Akt1, Akt2, mTOR, and RIPK3 (ON-TARGETplus SMARTpool) was obtained from Thermo Fisher Scientific (Waltham, MA, USA). Twenty $\mathrm{nmol}$ of siRNA with lipofectamine 2000 was transfected into HT22 cells. The same concentration of nontarget siRNA (from Thermo Fisher Scientific) was used as control. Cells were cultured for 3 days and targeted gene expression was examined by western blot.

Western blotting. Cells were lysed in radio-immunoprecipitation assay buffer (10 mM HEPES buffer, pH 7.6, $42 \mathrm{mM} \mathrm{KCl}, 5 \mathrm{mM} \mathrm{MgCl}, 1 \%$ SDS, $1 \mathrm{mM}$ phenylmethylsulfonylfluoride, $1 \mathrm{mM}$ EDTA (ethylenediaminetetraacetic acid), $1 \mathrm{mM}$ ethylene glycol tetraacetic acid, $1 \mathrm{mM}$ dithiothreitol, $1.5 \mu \mathrm{M}$ pepstatin, $2 \mu \mathrm{M}$ leupeptin, and $0.7 \mu \mathrm{M}$ aprotinin). Protein concentration was determined using the DCTM protein assay (Bio-Rad, Hercules, CA, USA). Thirty to fifty micrograms of protein was applied for polyacrylamide gel electrophoresis. The primary antibodies against HMGB1 (1:500), RIPK3 (1:1000), Akt1 (1:500), Akt2 (1:500), Akt3 (1:500), Akt (1:500), mTOR (1:500), phospho (Ser-473)-Akt (1:500), phospho (Ser308)-Akt (1:500), phospho (Ser9)-GSK-3 $\beta(1: 1000)$, phospho (Ser235/236)S6 $(1: 1000)$, and phospho (ser2448)-mTOR $(1: 1000)$ were obtained from Cell Signaling. Horseradish peroxidase conjugated secondary antibodies (1:10000) were used for ECL-plus (GE Healthcare, Pittsburgh, PA, USA) detection. The results were normalized to $\beta$-actin $(1: 5000)$.

Immunoprecipitation. For co-immunoprecipitation experiments, a total of $1.8 \mathrm{mg}$ of protein from HT22 cells was used. Cells were stimulated with TNF $\alpha$ $(1 \mathrm{ng} / \mathrm{ml})$ and $\mathrm{ZVAD}(50 \mu \mathrm{M})$ in the presence or absence of Necrostatin-1 $(30 \mu \mathrm{M})$, Akt Inhibitor VIII $10 \mu \mathrm{M})$, or rapamycin $(100 \mathrm{nM})$ for $2 \mathrm{~h}$. Cells were collected, washed in PBS and lysed in a buffer containing $20 \mathrm{mM}$ Tris- $\mathrm{HCl}(\mathrm{pH}$ 8), $137 \mathrm{mM}$
$\mathrm{NaCl}, 10 \%$ glycerol, $1 \%$ Nonidet P-40 (NP-40), $2 \mathrm{mM} \mathrm{EDTA}$, and protease inhibitor cocktail. Precleaning was achieved with $50 \mu$ l of protein $A / G$ agarose beads (Santa Cruz, Dallas, TX, USA) for $1 \mathrm{~h}$, and lysates were incubated overnight at $4{ }^{\circ} \mathrm{C}$ in presence of $50 \mu \mathrm{l}$ of protein $\mathrm{A} / \mathrm{G}$ agarose or magnetic beads and $1-2 \mu \mathrm{g}$ mouse anti-RIP1 antibody (BD Transduction) before analysis by western blotting. The same amount of irrelevant mouse IgG (Santa Cruz) was used to control for nonspecific IgG binding to RIPK1.

Measurement of ROS. HT22 cells were incubated with 5 uM MitoSOX Red for $10 \mathrm{~min}$ at $37^{\circ} \mathrm{C}$. Cells were washed in PBS and analyzed by fluorescence microscopy. Mitosox-positive cells were expressed as a percentage of total cells in 3-6 $\times 200$ fields/well, three wells per experiment. Experiments were repeated four times.

Statistical analysis. All values were expressed as mean \pm S.E.M. Data from more than two groups were assessed by one-way ANOVA, followed by Tukey's multiple comparison test using Graph Pad Prism V software (La Jolla, CA, USA). For all experiments, $P<0.05$ was considered statistically significant.

\section{Conflict of Interest}

The authors declare no conflict of interest.

Acknowledgements. This work was supported by NIH/NINDS 5R01NSO64545 (MJW) and National Natural Science Foundation of China grant 31371083

1. Vandenabeele P, Galluzzi L, Vanden Berghe T, Kroemer G. Molecular mechanisms of necroptosis: an ordered cellular explosion. Nat Rev Mol Cell Biol 2010; 11: 700-714

2. Degterev A, Huang Z, Boyce M, Li Y, Jagtap P, Mizushima N et al. Chemical inhibitor of nonapoptotic cell death with therapeutic potential for ischemic brain injury. Nat Chem Biol 2005; 1: 112-119.

3. You Z, Savitz SI, Yang J, Degterev A, Yuan J, Cuny GD et al. Necrostatin-1 reduces histopathology and improves functional outcome after controlled cortical impact in mice. J Cereb Blood Flow Metab 2008; 28: 1564-1573.

4. Zhao J, Jitkaew S, Cai Z, Choksi S, Li Q, Luo J et al. Mixed lineage kinase domain-like is a key receptor interacting protein 3 downstream component of TNF-induced necrosis. Proc Natl Acad Sci USA 2012; 109: 5322-5327.

5. Sun L, Wang H, Wang Z, He S, Chen S, Liao D et al. Mixed lineage kinase domain-like protein mediates necrosis signaling downstream of RIP3 kinase. Cell 2012; 148: 213-227.

6. Wang $Z$, Jiang $H$, Chen S, Du F, Wang $X$. The mitochondrial phosphatase PGAM5 functions at the convergence point of multiple necrotic death pathways. Cell 2012; 148 : 228-243.

7. O'Donnell MA, Ting AT. NFkappaB and ubiquitination: partners in disarming RIPK1-mediated cell death. Immunol Res 2012; 54: 214-226.

8. Laird MD, Wakade C, Alleyne Jr CH, Dhandapani KM. Hemin-induced necroptosis involves glutathione depletion in mouse astrocytes. Free Radic Biol Med 2008; 45: 1103-1114.

9. Li Y, Yang X, Ma C, Qiao J, Zhang C. Necroptosis contributes to the NMDA-induced excitotoxicity in rat's cultured cortical neurons. Neurosci Lett 2008; 447: 120-123.

10. Yamanaka K, Saito Y, Yamamori T, Urano Y, Noguchi N. 24(S)-hydroxycholesterol induces neuronal cell death through necroptosis, a form of programmed necrosis. $J$ Biol Chem 2011; 286: 24666-24673.

11. Park J, Zhang J, Qiu J, Zhu X, Degterev A, Lo EH et al. Combination therapy targeting Akt and mammalian target of rapamycin improves functional outcome after controlled cortical impact in mice. J Cereb Blood Flow Metab 2012; 32: 330-340.

12. Degterev A, Hitomi J, Germscheid M, Ch'en IL, Korkina O, Teng X et al. Identification of RIP1 kinase as a specific cellular target of necrostatins. Nat Chem Biol 2008; 4: 313-321.

13. Teng X, Degterev A, Jagtap P, Xing X, Choi S, Denu R et al. Structure-activity relationship study of novel necroptosis inhibitors. Bioorg Med Chem Lett 2005; 15: 5039-5044.

14. Christofferson DE, Li Y, Hitomi J, Zhou W, Upperman C, Zhu H et al. A novel role for RIP1 kinase in mediating TNFalpha production. Cell Death Dis 2012; 3: e320.

15. Cho YS, Challa S, Moquin D, Genga R, Ray TD, Guildford M et al. Phosphorylation-driven assembly of the RIP1-RIP3 complex regulates programmed necrosis and virus-induced inflammation. Cell 2009; 137: 1112-1123.

16. He S, Wang L, Miao L, Wang T, Du F, Zhao L et al. Receptor interacting protein kinase-3 determines cellular necrotic response to TNF-alpha. Cell 2009; 137: 1100-1111.

17. Zhang DW, Shao J, Lin J, Zhang N, Lu BJ, Lin SC et al. RIP3, an energy metabolism regulator that switches TNF-induced cell death from apoptosis to necrosis. Science 2009: 325: 332-336.

18. Kamata H, Honda S, Maeda S, Chang L, Hirata H, Karin M. Reactive oxygen species promote TNFalpha-induced death and sustained JNK activation by inhibiting MAP kinase phosphatases. Cell 2005; 120: 649-661. 
19. Kalyanaraman B, Darley-Usmar V, Davies KJ, Dennery PA, Forman HJ, Grisham MB et al. Measuring reactive oxygen and nitrogen species with fluorescent probes: challenges and limitations. Free Radic Biol Med 2012; 52: 1-6.

20. van Leyen K, Arai K, Jin G, Kenyon V, Gerstner B, Rosenberg PA et al. Novel lipoxygenase inhibitors as neuroprotective reagents. J Neurosci Res 2008; 86: 904-909.

21. Yigitkanli K, Pekcec A, Karatas H, Pallast S, Mandeville E, Joshi N et al. Inhibition of 12 15-lipoxygenase as therapeutic strategy to treat stroke. Ann Neurol 2013; 73: 129-135.

22. Los M, Maddika S, Erb B, Schulze-Osthoff K. Switching Akt: from survival signaling to deadly response. Bioessays 2009; 31: 492-495.

23. McNamara CR, Ahuja R, Osafo-Addo AD, Barrows D, Kettenbach A, Skidan I et al. Akt regulates TNFalpha synthesis downstream of RIP1 kinase activation during necroptosis. PLoS One 2013; 8: e56576.

24. Nogueira V, Park Y, Chen CC, Xu PZ, Chen ML, Tonic I et al. Akt determines replicative senescence and oxidative or oncogenic premature senescence and sensitizes cells to oxidative apoptosis. Cancer Cell 2008; 14: 458-470.

25. Rosenbaum DM, Degterev A, David J, Rosenbaum PS, Roth S, Grotta JC et al. Necroptosis, a novel form of caspase-independent cell death, contributes to neuronal damage in a retinal ischemia-reperfusion injury model. J Neurosci Res 2010; 88: 1569-1576.

26. Northington FJ, Chavez-Valdez R, Graham EM, Razdan S, Gauda EB, Martin LJ. Necrostatin decreases oxidative damage, inflammation, and injury after neonatal $\mathrm{HI}$. J Cereb Blood Flow Metab 2012; 31: 178-189.

27. Kim YS, Morgan MJ, Choksi S, Liu ZG. TNF-induced activation of the Nox1 NADPH oxidase and its role in the induction of necrotic cell death. Mol Cell 2007; 26: 675-687.

28. Yu L, Alva A, Su H, Dutt P, Freundt E, Welsh S et al. Regulation of an ATG7-beclin 1 program of autophagic cell death by caspase-8. Science 2004; 304: 1500-1502.

29. Friguls B, Petegnief V, Justicia C, Pallas M, Planas AM. Activation of ERK and Akt signaling in focal cerebral ischemia: modulation by TGF-alpha and involvement of NMDA receptor. Neurobiol Dis 2002; 11: 443-456.

30. Kilic E, Kilic U, Soliz J, Bassetti CL, Gassmann M, Hermann DM. Brain-derived erythropoietin protects from focal cerebral ischemia by dual activation of ERK-1/-2 and Akt pathways. FASEB J 2005; 19: 2026-2028.

31. Kilic E, Kilic U, Wang Y, Bassetti CL, Marti HH, Hermann DM. The phosphatidylinositol-3 kinase/Akt pathway mediates VEGF's neuroprotective activity and induces blood brain barrier permeability after focal cerebral ischemia. FASEB J. 2006; 20: 1185-1187.

32. Kitagawa H, Warita H, Sasaki C, Zhang WR, Sakai K, Shiro Y et al. Immunoreactive Akt, PI3-K and ERK protein kinase expression in ischemic rat brain. Neurosci Lett 1999; 274: $45-48$.

33. Li F, Omori N, Jin G, Wang SJ, Sato K, Nagano I et al. Cooperative expression of survival p-ERK and p-Akt signals in rat brain neurons after transient MCAO. Brain Res 2003; 962 : $21-26$.

34. Noshita N, Lewen A, Sugawara T, Chan PH. Akt phosphorylation and neuronal survival after traumatic brain injury in mice. Neurobiol Dis 2002; 9: 294-304.

35. Ohba N, Kiryu-Seo S, Maeda M, Muraoka M, Ishii M, Kiyama H. Transgenic mouse overexpressing the Akt reduced the volume of infarct area after middle cerebral artery occlusion. Neurosci Lett 2004; 359: 159-162.

36. Shioda N, Ishigami T, Han F, Moriguchi S, Shibuya M, Iwabuchi Y et al. Activation of phosphatidylinositol 3-kinase/protein kinase B pathway by a vanadyl compound mediates its neuroprotective effect in mouse brain ischemia. Neuroscience 2007; 148: 221-229.

37. Song YS, Narasimhan P, Kim GS, Jung JE, Park EH, Chan PH. The role of Akt signaling in oxidative stress mediates NF-kappaB activation in mild transient focal cerebral ischemia. $J$ Cereb Blood Flow Metab 2008; 28: 1917-1926.

38. Wang HY, Wang GL, Yu YH, Wang Y. The role of phosphoinositide-3-kinase/Akt pathway in propofol-induced postconditioning against focal cerebral ischemia-reperfusion injury in rats. Brain Res 2009; 1297: 177-184

39. Wu H, Lu D, Jiang H, Xiong Y, Qu C, Li B et al. Increase in phosphorylation of Akt and its downstream signaling targets and suppression of apoptosis by simvastatin after traumatic brain injury. J Neurosurg 2008; 109: 691-698.
40. Zhang $X$, Chen $Y$, Ikonomovic MD, Nathaniel PD, Kochanek PM, Marion DW et al. Increased phosphorylation of protein kinase $B$ and related substrates after traumatic brain injury in humans and rats. J Cereb Blood Flow Metab 2006; 26: 915-926.

41. Franke TF. PI3K/Akt: getting it right matters. Oncogene 2008; 27: 6473-6488.

42. Gottlob K, Majewski N, Kennedy S, Kandel E, Robey RB, Hay N. Inhibition of early apoptotic events by Akt/PKB is dependent on the first committed step of glycolysis and mitochondrial hexokinase. Genes Dev 2001; 15: 1406-1418.

43. Manning BD, Tee AR, Logsdon MN, Blenis J, Cantley LC. Identification of the tuberous sclerosis complex-2 tumor suppressor gene product tuberin as a target of the phosphoinositide 3-kinase/akt pathway. Mol Cell 2002; 10: 151-162.

44. Komandirov MA, Knyazeva EA, Fedorenko YP, Rudkovskii MV, Stetsurin DA, Uzdensky $A B$. On the role of phosphatidylinositol 3-kinase, protein kinase B/Akt, and glycogen synthase kinase-3beta in photodynamic injury of crayfish neurons and glial cells. $\mathrm{J} \mathrm{Mol}$ Neurosci 2011; 45: 229-235.

45. Aki T, Yamaguchi K, Fujimiya T, Mizukami Y. Phosphoinositide 3-kinase accelerates autophagic cell death during glucose deprivation in the rat cardiomyocyte-derived cell line H9c2. Oncogene 2003; 22: 8529-8535.

46. Lu B, Wang L, Stehlik C, Medan D, Huang C, Hu S et al. Phosphatidylinositol 3-kinase/Akt positively regulates Fas (CD95)-mediated apoptosis in epidermal $\mathrm{Cl} 41$ cells. J Immunol 2006; 176: 6785-6793.

47. Nimbalkar D, Henry MK, Quelle FW. Cytokine activation of phosphoinositide 3-kinase sensitizes hematopoietic cells to cisplatin-induced death. Cancer Res 2003; 63: 1034-1039.

48. Shack S, Wang XT, Kokkonen GC, Gorospe M, Longo DL, Holbrook NJ. Caveolin-induced activation of the phosphatidylinositol 3-kinase/Akt pathway increases arsenite cytotoxicity. Mol Cell Biol 2003; 23: 2407-2414.

49. Maddika S, Wiechec E, Ande SR, Poon IK, Fischer U, Wesselborg S et al. Interaction with PI3-kinase contributes to the cytotoxic activity of apoptin. Oncogene 2008; 27: 3060-3065.

50. Maddika S, Bay GH, Kroczak TJ, Ande SR, Wiechec E, Gibson SB et al. Akt is transferred to the nucleus of cells treated with apoptin, and it participates in apoptin-induced cell death. Cell Prolif 2007; 40: 835-848.

51. Kops GJ, Dansen TB, Polderman PE, Saarloos I, Wirtz KW, Coffer PJ et al. Forkhead transcription factor FOXO3a protects quiescent cells from oxidative stress. Nature 2002; 419: 316-321.

52. Nemoto S, Finkel T. Redox regulation of forkhead proteins through a p66shc-dependent signaling pathway. Science 2002; 295: 2450-2452.

53. Greer EL, Brunet A. FOXO transcription factors at the interface between longevity and tumor suppression. Oncogene 2005; 24: 7410-7425.

54. Plas DR, Thompson CB. Akt activation promotes degradation of tuberin and FOXO3a via the proteasome. J Biol Chem 2003; 278: 12361-12366.

55. Huang H, Regan KM, Wang F, Wang D, Smith DI, van Deursen JM et al. Skp2 inhibits FOXO1 in tumor suppression through ubiquitin-mediated degradation. Proc Natl Acad Sci USA 2005; 102: 1649-1654.

56. Alvarez B, Martinez AC, Burgering BM, Carrera AC. Forkhead transcription factors contribute to execution of the mitotic programme in mammals. Nature 2001; 413: 744-747.

57. Maddika S, Ande SR, Wiechec E, Hansen LL, Wesselborg S, Los M. Akt-mediated phosphorylation of CDK2 regulates its dual role in cell cycle progression and apoptosis. J Cell Sci 2008; 121(Pt 7): 979-988.

(c) (i) $(-)$ Cell Death and Disease is an open-access journal cublished by Nature Publishing Group. This work is licensed under a Creative Commons Attribution-NonCommercialNoDerivs 3.0 Unported License. To view a copy of this license, visit http://creativecommons.org/licenses/by-nc-nd/3.0/ 